\title{
NEW CONVOLUTIONS AND NORM INEQUALITIES
}

\section{P. CASTRO AND S. SAITOH}

Abstract. We introduce new three types of convolutions for which - together with the classical convolution - we obtain new convolution inequalities. This is done within a framework from the theory of reproducing kernels which helps us to perform the mentioned inequalities in a very global way.

Mathematics subject classification (2010): Primary 44A35; Secondary 30C40, 42A85, 45E10, 46E22, 47A30, 47B32, 47B38, 47G10.

Keywords and phrases: Integral transform, Hilbert space, linear transform, reproducing kernel, linear mapping, convolution, Toeplitz kernel, Hankel kernel, norm inequality.

\section{REFERENCES}

[1] R. Beals, Spatially inhomogeneous pseudodifferential operators II, Comm. Pure Appl. Math. 27 (1974), 161-205.

[2] G. Bogveradze and L. P. Castro, Toeplitz plus Hankel operators with infinite index, Integral Equations Operator Theory 62, 1 (2008), 43-63.

[3] G. Bogveradze And L. P. CAStro, Invertibility characterization of Wiener-Hopf plus Hankel operators via odd asymmetric factorizations, Banach J. Math. Anal. 3, 1 (2009), 1-18.

[4] J. W. Brown And R. V. Churchill, Fourier Series and Boundary Value Problems (4th edition), McGraw-Hill Book Co., New York, 1987.

[5] L. P. Castro, R. Duduchava And F.-O. SPeCK, Solvability of singular integro-differential equations with multiple complex shifts, Complex Anal. Oper. Theory 2, 2 (2008), 327-343.

[6] L. P. CASTRO AND A. P. NOlASCO, A semi-Fredholm theory for Wiener-Hopf-Hankel operators with piecewise almost periodic Fourier symbols, J. Operator Theory 62, 1 (2009), 3-31.

[7] L. P. CASTRO AND E. M. RoJAS, Reduction of singular integral operators with flip and their Fredholm property, Lobachevskii J. Math. 29, 3 (2008), 119-129.

[8] L. P. CASTRO AND E. M. RoJAS, Explicit solutions of Cauchy singular integral equations with weighted Carleman shift, J. Math. Anal. Appl. 371, 1 (2010), 128-133.

[9] L. P. CASTRO AND E. M. RojAs, On the invertibility of singular integral equations with reflection on the unit circle, Integral Equations and Operator Theory 70 (2011), 63-99.

[10] L. P. CASTRO AND A. S. Silva, Invertibility of matrix Wiener-Hopf plus Hankel operators with symbols producing a positive numerical range, Z. Anal. Anwend. 28, 1 (2009), 119-127.

[11] R. V. ChURChILl, Fourier Series and Boundary Value Problems, McGraw-Hill, New York, 1941.

[12] D. T. Duc AND N. D. V. NHAN, On some convolution norm inequalities in weighted $L_{p}\left(\mathbb{R}^{n}, \rho\right)$ spaces and their applications, Math. Inequal. Appl. 11, 3 (2008), 495-505.

[13] D. T. DuC AND N. D. V. Nhan, On some reverse weighted $L_{p}\left(\mathbb{R}^{n}\right)$-norm inequalities in convolutions and their applications, Math. Inequal. Appl. 12, 1 (2009), 67-80.

[14] D. T. Duc And N. D. V. Nhan, Some applications of convolution inequalities in weighted $L_{p}$ spaces, Integral Transforms Spec. Funct. 19, 7-8 (2008), 471-480.

[15] G. I. ÈsKIn, Degenerate elliptic pseudodifferential equations of principal type (Russian), Mat. Sb. (N.S.) 82 (124) (1970), 585-628.

[16] A. Greenleaf And G. Uhlmann, Estimates for singular Radon transforms and pseudodifferential operators with singular symbols, J. Funct. Anal. 89, 1 (1990), 202-232.

[17] L. HöRmANDER, Fourier integral operators I, Acta Math. 127, 1-2 (1971), 79-183. 
[18] V. A. KAKICHEV, On the convolutions for integral transforms (Russian), Vestsi Akad. Navuk BSSR Ser. Fiz.-Mat. Navuk 22 (1967), 48-57.

[19] N. D. V. Nhan, D. T. DUC AND V. K. TuAN, Weighted $L_{p}$-norm inequalities for various convolution type transformations and their applications, Armen. J. Math. 1, 4 (2008), 1-18.

[20] N. D. V. NHAN AND D. T. Duc, Fundamental inequalities for the iterated Laplace convolution in weighted $L_{p}$ spaces and their applications, Integral Transforms Spec. Funct. 19, 9-10 (2008), 655664.

[21] N. D. V. Nhan AND D. T. Duc, Reverse weighted $L_{p}$-norm inequalities and their applications, J. Math. Inequal. 2, 1 (2008), 57-73.

[22] N. D. V. Nhan AND D. T. DUC, Weighted $L_{p}$-norm inequalities in convolutions and their applications, J. Math. Inequal. 2, 1 (2008), 45-55.

[23] S. SAItOH, A fundamental inequality in the convolution of $L_{2}$ functions on the half line, Proc. Amer. Math. Soc. 91 (1984), 285-286.

[24] S. SAITOH, On the convolution of $L_{2}$ functions, Kodai-Math. J. 9 (1986), 50-57.

[25] S. S Aitoh, Integral Transforms, Reproducing Kernels and their Applications, Pitman Research Notes in Mathematics Series 369. Longman, Harlow, 1997.

[26] S. SAItoH, Inequalities in the most simple Sobolev space and convolutions of $L_{2}$ functions with weights, Proc. Amer. Math. Soc. 118 (1999), 515-520.

[27] S. SAitoh, Weighted $L_{p}$-norm inequalities in convolutions. Survey on Classical Inequalities, 225234, Math. Appl. 517, Kluwer Acad. Publ., Dordrecht, 2000.

[28] S. SAITOH, V. K. TUAN, AND M. YAMAMOTO, Reverse convolution inequalities and applications to inverse heat source problems, J. Inequal. Pure Appl. Math. 3, 5 (2002), Article 80, 11 pp.

[29] S. SAITOH, Theory of reproducing kernels; applications to approximate solutions of bounded linear operator equations on Hilbert spaces, Amer. Math. Soc. Transl. 230 (2010), 107-134.

[30] L. P. CASTRO, A. Silva AND S. SAITOH, Integral equations with mixed Toeplitz and Hankel kernels, manuscript.

[31] H. HochstaDT, Integral Equations, John Wiley \& Sons, N. Y., 1973.

[32] N. D. V. Nhan AND D. T. DUC, Norm inequalities for new convolutions and their applications, manuscript.

[33] A. YAMADA, Equality conditions for general norm inequalities in reproducing kernel Hilbert spaces, Advances in Analysis, World Scientific, 2005, 447-455. 